\title{
APLICAÇÃO FOLIAR DE MOLIBDÊNIO DURANTE A MATURAÇÃO DE SEMENTES DE SOJA
}

\author{
Leaf application of molybdenum during soybean seed maturation
}

\author{
Gustavo Lima Milani' ${ }^{1}$, João Almir Oliveira ${ }^{2}$, Elise de Matos Pereira ${ }^{3}$, Bruno Oliveira Carvalho ${ }^{3}$, \\ Gustavo Evagelista Oliveira ${ }^{3}$, Ricardo Resende Costa ${ }^{3}$
}

\begin{abstract}
RESUMO
A aplicação foliar, objetivando o acúmulo do nutriente na semente, é uma tecnologia recente e, por isso, pouco se sabe sobre o seu efeito na qualidade fisiológica e a influência da sua aplicação sobre a produtividade das plantas. Neste Trabalho objetivou-se avaliar a produtividade das plantas que receberam a aplicação de Mo via foliar em diferentes doses, e a qualidade fisiológica das sementes provenientes dessas plantas. A fonte de molibdênio usada foi o molibdato de sódio ( $39 \% \mathrm{Mo}$ ). As sementes receberam o Mo por meio de aplicações foliares durante o processo de maturação, em aplicação única e parcelada em duas vezes, feitas entre os estágios R5.2 e R5.4, em dois ensaios, em Lavras e Ituiutaba, MG. Os tratamentos para os dois ensaios foram: aplicação de 1000g, de 800g, $600 \mathrm{~g}$, de 400g, 2 aplicações de 500g, de 400g, de 300g, de 200g por hectare e $0 \mathrm{~g}$ (testemunha). Os ensaios foram instalados em DBC, com quatro repetições. Avaliou-se o teor de Mo na semente, a produtividade das plantas que receberam a aplicação foliar e a qualidade fisiológica nos testes de germinação, IVE, teste de frio e condutividade elétrica. O teor de Mo nas sementes de soja é crescente com a dose aplicada nas plantas e independe da aplicação em dose única ou parcelada. O acúmulo de Mo nas sementes não interfere na produtividade e na qualidade fisiológica das sementes soja.
\end{abstract}

Termos para indexação: Glycine max, molibdênio, produtividade, qualidade fisiológica.

\section{ABSTRACT}

Leaf application with the objective of accumulating this nutrient in the seed is a new technology so its effects on the physiological quality and influence in the yield of the plants are little known. The objective of this study was to evaluate the yield of the plants that underwent leaf application of Mo at different rates, and the physiological quality of soybean seeds resulting from those plants. The source of molybdenum used was sodium molybdate $(39 \% \mathrm{Mo})$. The seeds received Mo through leaf applications during the maturation process, in one application divided twice, made between R5.2 and R5.4 stages, in two tests, in Lavras and Ituiutaba, MG. The treatments of the two assays were: application of $1000 \mathrm{~g}$; of $800 \mathrm{~g}$; of $600 \mathrm{~g}$; of $400 \mathrm{~g}$; two applications of 500g; 400g; 300g; 200g per ha and 0g (control). The tests were made in DBC, with four replicates. Mo content in seed, yield of the plants that received the leaf application and the physiological quality the tests of germination, EVI, cold test and conductivity electrical were evaluated. The content of Mo in the seed is directly proportional to the quantity applied to the plants regardless of there being only one application or divided. The accumulation of Mo in the seeds does not affect the yield and the physiological quality of soybean seeds.

Index terms: Glycine max, molybdenum, yield, physiological quality.

\section{(Recebido em 17 de março de 2009 e aprovado em 16 de março de 2010)}

\section{INTRODUÇÃO}

Atualmente, o Brasil figura entre os três maiores produtores de soja do mundo. A área plantada na safra 2007/2008 foi de 21.313.000 ha, com produtividade média

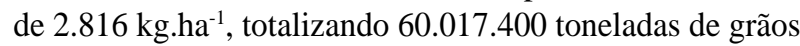
(Companhia Nacional de Abastecimento - CONAB, 2008). Para suprir essa demanda, seria necessária a produção de aproximadamente 1.400 .000 toneladas de sementes de soja. Entretanto, de acordo com levantamentos recentes, a demanda efetiva de sementes ficou em torno de 800.000 toneladas. Chega-se à conclusão de que a taxa de utilização de sementes de soja no Brasil ainda é baixa, com média nacional de 57\% (Associação Brasileira de Sementes e Mudas - ABRASEM, 2008), mesmo sendo caracterizada como cultura de alta tecnologia. $\mathrm{O}$ volume de sementes de soja corresponde a $52 \%$ do total de sementes produzidas e a $37 \%$ do faturamento nesse setor.

Haja vista a importância econômica da sojicultura para o Brasil, o estudo contínuo dessa espécie faz-se necessário. As pesquisas dessa leguminosa são importantes em todos os aspectos, inclusive as relacionadas com uma importante característica da planta, que é a sua capacidade de fixar nitrogênio atmosférico, por

1Universidade Federal de Lavras/UFLA - Cx. P. 3037 - 37200-000 - Lavras, MG - glimamilani@yahoo.com.br
'Universidade Federal de Lavras/UFLA - Departamento de Agricultura/DAG - Lavras, MG

${ }^{3}$ Universidade Federal de Lavras/UFLA - Lavras, MG

Ciênc. agrotec., Lavras, v. 34, n. 4, p. 810-816, jul./ago., 2010 
meio do processo de fixação biológica de nitrogênio (FBN), resultante da simbiose com bactérias do gênero Bradyrhizobium.

Em razão da sua grande importância no processo de FBN, o molibdênio é, dentre os micronutrientes exigidos pela soja, o que apresenta resposta mais frequente e consistente na produtividade, não sendo exportado pelos grãos em grande quantidade (Fundação de Apoio à Pesquisa Agropecuária de Mato Grosso - Fundação MT, 2004). Segundo Vargas \& Hungria (1997), o molibdênio (Mo) é um micronutriente de grande importância no processo de fixação biológica de nitrogênio atmosférico, propiciando grandes incrementos no rendimento da soja quando fornecido adequadamente à planta. Dentro do processo de fixação biológica de nitrogênio, o Mo participa como um dos catalizadores da enzima nitrogenase, que é responsável pela transformação do $\mathrm{N}$ atmosférico em amônia. Esse elemento também participa do complexo enzimático da nitrato redutase, responsável pela assimilação do nitrato pelas plantas, atuando como doador de elétrons (Taiz \& Zeiger, 2004).

Existem três maneiras de fornecer Mo à soja: por meio do tratamento de sementes, da aplicação foliar e da utilização de sementes que contenham teores suficientes para o bom desenvolvimento das plantas. Entretanto, o fornecimento de Mo é feito, na maioria das vezes, por meio do tratamento de sementes. Contudo, em vários estudos, concluiu-se que a aplicação do Mo via semente reduz a nodulação e a eficiência da FBN, sendo a aplicação foliar uma das alternativas para solucionar este problema (Hungria et al., 2001; Câmara et al., 2002; Moreira \& Siqueira, 2002). Outra alternativa para esse problema seria a utilização de sementes enriquecidas com Mo (Campo \& Hungria, 2003), apresentando, essas sementes, um conteúdo ideal desse micronutriente, deverão ter maior valor comercial.

Guimarães (1999) afirma que a composição química das sementes é determinada, basicamente, por fatores genéticos, embora possa ter influência do ambiente e das práticas culturais, sendo o fornecimento de nutrientes o parâmetro de mais fácil controle entre os que afetam a composição química das sementes. A concentração de nutrientes minerais nas sementes pode afetar o seu potencial de armazenamento, bem como o desenvolvimento inicial das plantas, a fixação biológica de nitrogênio, no caso das leguminosas, e a produção de grãos das plantas por elas geradas (Jacob-Neto \& Rosseto, 1998).

O enriquecimento de sementes com molibdênio é uma técnica pouco estudada, com relação ao efeito da aplicação foliar de Mo durante o processo de maturação, com o objetivo de enriquecer a semente e seu efeito sobre a produtividade da planta e a qualidade fisiológica das sementes. Desse modo, neste trabalho, foram avaliadas a produtividade e a qualidade fisiológica de sementes de soja provenientes de plantas submetidas à adubação foliar com Mo durante o processo de maturação.

\section{MATERIAIS E MÉTODOS}

Os trabalhos foram conduzidos no Laboratório de Análises de Sementes (LAS) da Universidade Federal de Lavras (UFLA) e em áreas experimentais em Lavras, MG (Ensaio 1) e Ituiutaba, MG (Ensaio 2).

\section{Ensaio 1}

Esse ensaio foi conduzido na área experimental do Departamento de Agricultura da Universidade Federal de Lavras (UFLA). O município de Lavras está localizado na Região Sul de Minas Gerais, latitude $21^{\circ} 14^{\prime}$ S e longitude $40^{\circ} 17^{\prime} \mathrm{W}$ e a $918 \mathrm{~m}$ de altitude.

O material genético utilizado foi composto por sementes de soja da cultivar Conquista, produzidas pela Sementes Farroupilha. As sementes foram tratadas com o fungicida Tegran ${ }^{\circledR}$, na dosagem de $200 \mathrm{~g} / 100 \mathrm{~kg}$ de sementes e inoculadas com bactérias do gênero Bradirhizobium, utilizando-se o inoculante turfoso Masterfix Soja (SEMIA 5019 E SEMIA 5079) com concentração mínima de $5 \times 10^{9}$ células viáveis/grama, numa dosagem de $200 \mathrm{~g} / 50 \mathrm{~kg}$ de sementes. O solo foi preparado convencionalmente. Após a inoculação, procedeu-se a semeadura em sulcos a quatro centímetros de profundidade. Cada parcela foi constituída de quatro linhas de $5 \mathrm{~m}$ de comprimento, espaçadas 0,50 $\mathrm{m}$ entre linhas, considerando-se como área útil as duas linhas centrais.

Foram distribuídas 20 sementes por metro, realizando-se o desbaste da parcela útil 30 dias após a semeadura, deixando-se 60 plantas por linha. Foi utilizada a formulação 0-18-20 de NPK na semeadura, na dosagem

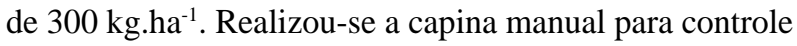
de plantas invasoras aos 15 e 30 dias após o plantio. A partir daí, foram realizadas uma pulverização com Tamaron $\mathrm{BR}^{\circledR}$, na dosagem de $500 \mathrm{~mL} \cdot \mathrm{ha}^{-1}$, para o controle de diabrótica e duas pulverizações com Sphere ${ }^{\circledR}$, na dosagem de 400 mL.ha- e 200 L.ha $^{-1}$ de calda, para o controle da ferrugem asiática (Phakopsora pachirizi).

Nesse experimento, foram produzidas as sementes enriquecidas com Mo, a partir da aplicação foliar da fonte molibdato de sódio (39\% de Mo), com diferentes doses em uma única aplicação ou parcelada em duas aplicações. As doses aplicadas foram $1000 \mathrm{~g}, 800 \mathrm{~g}, 600 \mathrm{~g}, 400 \mathrm{~g}$ e $0 \mathrm{~g}$ (testemunha) de Mo por hectare. A aplicação única foi realizada no estádio de desenvolvimento R 5.2, e, no caso da parcelada, em duas aplicações, realizadas nos estágios 
R 5.2 e R 5.4, por meio de bomba manual de alta pressão (1,5 L). O volume de calda utilizado nas aplicações foi de 400 L.ha ${ }^{-1}$.

A colheita das sementes ocorreu manualmente com o arranquio da plantas da parcela útil, quando as sementes atingiram $15 \%$ de grau de umidade. As plantas foram secadas ao sol e, quando as sementes se encontraram com umidade próxima de $13 \%$, realizou-se a debulha manual. Após a limpeza das sementes, por meio de peneiras, determinaram-se o peso e o grau de umidade, sendo, posteriormente, embaladas em sacos de papel e armazenadas em câmara fria, a $10^{\circ} \mathrm{C}$ e $50 \%$ de UR, até a realização das análises.

\section{Ensaio 2}

Esse ensaio, foi conduzido na Fazenda Bebedouro, no município de Ituiutaba-MG. A cidade está localizada na região do Pontal do Triângulo Mineiro, latitude $19^{\circ} 00^{\prime} \mathrm{S}$ e longitude $49^{\circ} 29^{\prime} \mathrm{W}$ e a $605 \mathrm{~m}$ de altitude.

O material genético utilizado foi a cultivar CD-215, produzidas pela COODETEC. As sementes foram tratadas com o fungicida Vitavax-Thiram ${ }^{\circledR}$, na dosagem de $250 \mathrm{~g} / 100$ $\mathrm{kg}$ de sementes e inoculadas com bactérias do gênero Bradyrhizobium, utilizando-se o inoculante turfoso AGROCETE $^{\circledR}$ (SEMIA 5019 E SEMIA 587) com concentração mínima de $1 \times 10^{9}$ células viáveis/grama, numa dosagem de $500 \mathrm{~g} / 50 \mathrm{~kg}$ de sementes. Após a inoculação, procedeu-se a semeadura no campo. A área foi dessecada com Glifosato Nortox ${ }^{\circledR}$, na dosagem de 4,0 L.ha ${ }^{-1}, 3$ dias antes da semeadura. A semeadura foi realizada a quatro centímetros de profundidade, pelo método de semeadura direta. Cada parcela foi constituída de quatro linhas de $5 \mathrm{~m}$ de comprimento, espaçadas $0,45 \mathrm{~m}$ entre linhas, considerando-se como área útil as duas linhas centrais.

Foram distribuídas 16 sementes por metro. Após a emergência de plântulas, foi feito o desbaste deixando 60 plantas por linha. Foi utilizada a formulação 2-20-10 de NPK na semeadura, na dosagem de $250 \mathrm{~kg} \cdot \mathrm{ha}^{-1}$. O controle de plantas invasoras foi feito com os herbicidas pós-emergentes Cobra $^{\circledR}$ e Gallant $\mathrm{R}^{\circledR}$ nas doses de 400 mL.ha $^{-1}$. A partir daí, foram realizadas uma pulverização com Gallaxy ${ }^{\circledR}$, na dosagem de 50 mL.ha- ${ }^{-1}$ e Cipermetrina Nortox ${ }^{\circledR}$, na dosagem de 50 $\mathrm{mL} \cdot \mathrm{ha}^{-1}$, e duas pulverizações para o controle da ferrugem asiática (Phakopsora pachirizi), a primeira com Sphere ${ }^{\circledR}$, na dosagem de 400 mL.ha ${ }^{-1}$ e a segunda com Folicur ${ }^{\circledR}$, na dosagem de $500 \mathrm{~mL} \cdot \mathrm{ha}^{-1}$. Uma pulverização adicional foi feita para o controle de percevejos com Tamaron $\mathrm{BR}^{\circledR}$, na dosagem de $500 \mathrm{~mL} \cdot \mathrm{ha}^{-1}$. Em todas as pulverizações, foram utilizados 200 L.ha ${ }^{-1}$ de calda.

Neste experimento, foram produzidas as sementes enriquecidas com Mo, seguindo a mesma metodologia, produto e dosagens bem como a colheita e o processamento pós-colheita também adotados no ensaio1.

\section{Avaliações}

Produtividade: Com o peso das amostras de cada parcela, que foi obtido logo após a colheita e com o grau de umidade das sementes no momento da pesagem, fez-se a correção de todas as amostras para $13 \%$ de grau de umidade, tendo os resultados sido transformados para $\mathrm{kg} / \mathrm{ha}$.

Determinação do teor de Mo nas sementes: A análise do teor de molibdênio nas sementes foi realizada no Centro de Energia Nuclear na Agricultura (CENA) da USP, campus de Piracicaba, SP. As amostras foram moídas e submetidas à digestão nitro-perclórica, com posterior leitura em aparelho de espectrometria de emissão ótica acoplado indutivamente ICP OES, Perkin Elmer (Optima 3000 DV).

Teste de germinação: A semeadura foi realizada em folhas de papel germitest, pelo sistema de rolos umedecidos com água, em quantidade equivalente a 2,5 vezes o peso do substrato seco. Os rolos foram colocados em germinadores à temperatura de $25^{\circ} \mathrm{C}$. No quinto dia, foram realizadas as contagens do número de plântulas normais, segundo as Regras para Análise de Sementes (RAS) (Brasil, 1992). Cada tratamento foi composto de quatro repetições com 50 sementes. Os resultados foram expressos em porcentagem de plântulas normais.

Teste de frio: A semeadura foi realizada em bandejas plásticas contendo substrato composto por areia + solo na proporção de $2: 1$, sendo o solo proveniente da área experimental da UFLA, que foi cultivado com soja nos três últimos anos. De acordo com as prescrições da International Seed Test Association, a umidade do substrato foi ajustada para $70 \%$ da capacidade de campo. Cada tratamento foi composto por quatro repetições de 50 sementes. Após a semeadura, as bandejas foram colocadas em câmara fria a $10^{\circ} \mathrm{C}$, por cinco dias. Posteriormente, foram transferidas para câmara de crescimento vegetal à temperatura de $25^{\circ} \mathrm{C}$, em regime alternado de luz e escuro (12 horas), onde permaneceram por mais sete dias, quando foi avaliado o número de plântulas normais emergidas.

Teste de emergência em bandeja: A semeadura foi realizada em bandejas plásticas contendo substrato composto por solo + areia na proporção de 2:1. A umidade do substrato foi ajustada para $60 \%$ da capacidade de campo. Cada tratamento foi composto por quatro repetições de 50 sementes. Após a semeadura, as bandejas foram mantidas em câmara de crescimento a $25^{\circ} \mathrm{C}$, em regime alternado de 
luz e escuro (12 horas). Foram realizadas avaliações diárias a partir do início da emergência, computando-se o número de plântulas emergidas até a estabilização. Foram computadas a porcentagem de plântulas normais aos 14 dias e o índice de velocidade de emergência, segundo a fórmula proposta por Maguire (1962).

Teste de condutividade elétrica: Cada tratamento foi composto por 4 repetições de 50 sementes que, após a pesagem de cada repetição, foram colocados em copos plásticos contendo $75 \mathrm{~mL}$ de água destilada. As sementes foram, então, colocadas em BOD, regulada para a temperatura de $25^{\circ} \mathrm{C}$, por período de 24 horas. As leituras foram realizadas em condutivímetro Digimed, modelo CD-21. Os resultados foram expressos em mmhos $\mathrm{cm}^{-1} \mathrm{~g}$ de sementes ${ }^{-1}$.

\section{Delineamento experimental}

Os experimentos, dos ensaios de campo, foram instalados em blocos casualizados (DBC) e os de laboratório em (DIC), com quatro repetições. Foi feito um fatorial 5 x 2 , sendo os fatores cinco doses de Mo em aplicação foliar (única e parcelada em duas aplicações). Foi realizada a análise de variância para o estudo das doses e a comparação entre médias para as aplicações. Para tanto, utilizou-se o programa estatístico Sisvar (Ferreira, 2000).

\section{RESULTADOS E DISCUSSÃO}

\section{Produtividade das plantas}

Nos dois ensaios não houve diferença significativa, para a produtividade das plantas de soja submetidas à aplicação foliar de Mo, em função das diferentes doses de Mo, da aplicação única e parcelada, assim como na interação destes dois fatores. A aplicação foliar de Mo em plantas de soja, durante o processo de maturação, com o objetivo específico de acumular este nutriente na semente, não foi tóxico e nem promoveu aumento da produção, mesmo nas altas doses aplicadas: 400, 600, 800 e 1000 g.ha- ${ }^{-1}$. Deve ser ressaltado também que o local e a cultivar não influenciaram nos resultados encontrados para esta variável.

Resultado semelhante foi observado por Vieira et al. (2002) que, estudando o acúmulo de molibdênio em sementes de feijão, por meio de aplicações foliares, constaram que a aplicação de altas doses de Mo (1.440 g.ha ${ }^{-1}$ ) não foi tóxica, não havendo diferença significativa na produtividade.

\section{Teor de Mo nas sementes enriquecidas}

Houve diferença significativa, pelo teste de F, para o teor de Mo acumulado na semente, em função das doses aplicadas na "planta-mãe" durante o enchimento de grãos, nos dois ensaios. Entretanto, não houve diferença, para a aplicação única e parcelada em duas vezes e nem para a interação das doses com a aplicação, tendo essas consequências sido observadas nos dois ensaios. Esse resultado não foi observado por Campo \& Hungria (2003), que afirmaram que o enriquecimento de sementes de soja, por meio de adubação foliar, pode ser feito, com aplicações foliares de Mo, sendo que aplicações parceladas em duas vezes apresentam resposta significativa, quando comparadas com uma aplicação.

Observa-se, pelas Figuras 1 e 2, que houve aumento linear e crescente do teor de Mo nas sementes com a aplicação de doses crescentes de molibdato nas plantas, tanto para as sementes colhidas em Lavras como em Ituiutaba. No entanto, nas sementes da cultivar CD-215 produzidas em Ituiutaba, foi observado um acúmulo mais acentuado de Mo, em relação à cultivar Conquista que foi produzida em Lavras. Na cultivar CD-215 para a maior dose aplicada (1000 g.ha-1), foram acumulados 104,65 $\mathrm{g} \mathrm{g} \mathrm{g}^{-1} \mathrm{e}$, para a cultivar Conquista, houve um acúmulo de apenas $48,05 \mu \mathrm{g} \mathrm{g}^{-1}$, nesta mesma dosagem.

Os resultados deste trabalho estão de acordo com aqueles obtidos por Campo \& Hungria (2004), os quais estudaram a aplicação de três doses de Mo: 800, 1200 e 1600 g.ha-1 . O maior acúmulo foi na dose de 1600 g.ha-1 na qual as sementes atingiram teor médio de $29,6 \mu \mathrm{g} \mathrm{g}^{-1}$. Leite et al. (2002) e Ferreira et al. (2003) também relatam que o de teor de Mo nas sementes é proporcional às doses aplicadas na planta-mãe na cultura do feijoeiro.

Nos dois ensaios realizados, mesmo para a menor dose aplicada (400 g.ha ${ }^{-1}$ ), as sementes continham teores superiores a $22.4 \mu \mathrm{g} \mathrm{g}^{-1}$ de Mo considerado suficiente (Harris et al., 1965) para que as plantas se desenvolvessem normalmente em solos com diversos graus de deficiência de Mo, mostrando que estas podem ser tidas como autossuficientes em Mo.

$\mathrm{O}$ teor de molibdênio que ocorre normalmente nas sementes de soja é de 1 a $2 \mu \mathrm{g} \mathrm{g}^{-1}$, valor próximo ao encontrado nas parcelas que não receberam o produto, nos dois ensaios. Entretanto, segundo dados apresentados na Reunião de Pesquisa de Soja da Região Sul (2001), essa concentração não é suficiente para suprir devidamente a planta.

\section{Qualidade fisiológica das sementes enriquecidas}

Com relação aos resultados dos testes utilizados para avaliar a qualidade fisiológica das sementes não houve diferença significativa para nenhum dos parâmetros avaliados, tanto nos fatores isolados como na interação, para ambos os ensaios (tabela 1 e 2). 


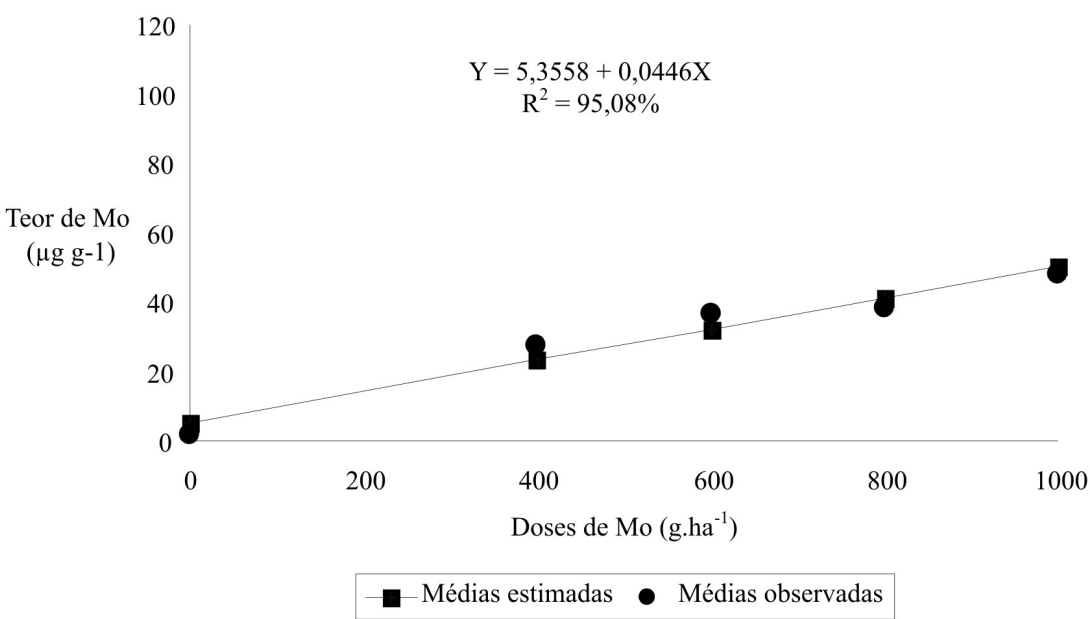

Figura 1 - Teor de Mo nas sementes de soja colhidas no ensaio 1, cultivar Conquista/Lavras, e enriquecidas em função da dose de Mo aplicada. UFLA, Lavras, MG, 2008.

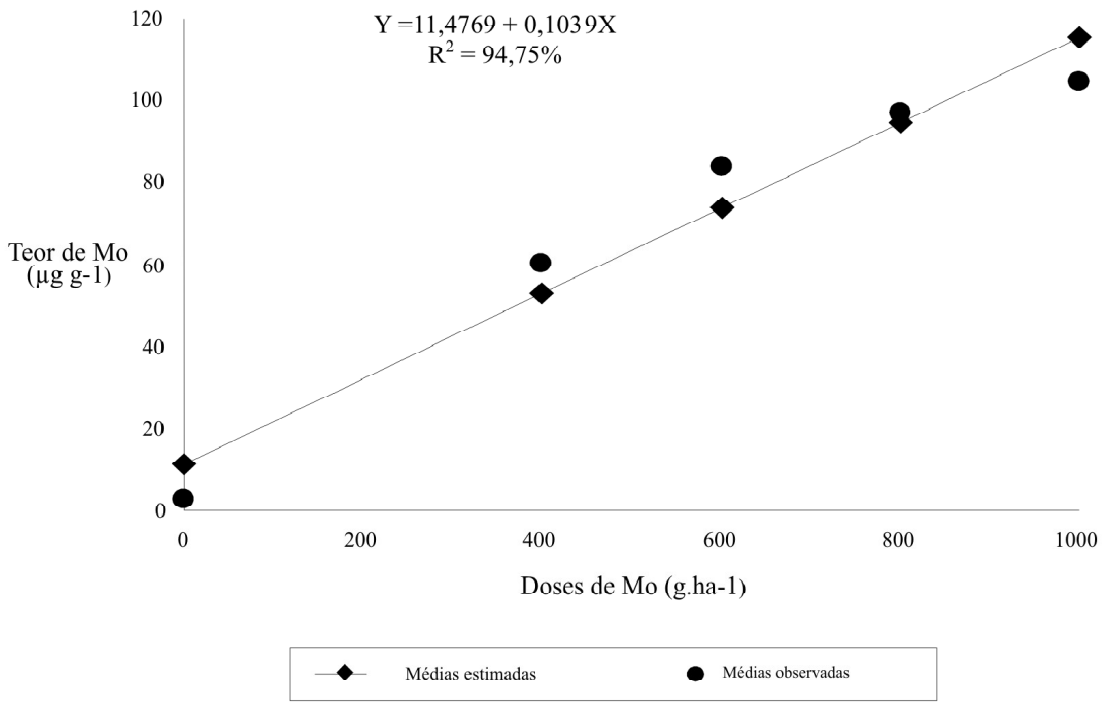

Figura 2 - Teor de Mo nas sementes de soja colhidas no ensaio 2, cultivar CD-215/Ituiutaba, e enriquecidas em função da dose aplicada. UFLA, Lavras, MG, 2008.

Tabela 1 - Porcentagem de germinação e emergência após teste de frio (TF), índice de velocidade de emergência (IVE) e condutividade elétrica de sementes de soja produzidas no ensaio 1, cultivar Conquista/Lavras, e enriquecidas com diferentes doses de Mo. UFLA, Lavras, MG, 2008

\begin{tabular}{lcccc}
\hline Doses & Germinação & TF & IVE & Condutividade \\
\hline 0 & 93,65 & 81,00 & 4,38 & 69,39 \\
400 & 93,00 & 80,62 & 4,24 & 69,70 \\
600 & 93,00 & 81,87 & 4,25 & 69,56 \\
800 & 93,75 & 80,37 & 4,29 & 70,84 \\
1000 & 92,00 & 80,25 & 4,37 & 74,44 \\
\hline
\end{tabular}

Ciênc. agrotec., Lavras, v. 34, n. 4, p. 810-816, jul./ago., 2010 
Tabela 2 - Porcentagem de germinação e emergência após teste de frio (TF), índice de velocidade de emergência (IVE) e condutividade elétrica de sementes de soja colhidas no ensaio 2, cultivar CD-215/Ituiutaba, e enriquecidas com diferentes doses de Mo. UFLA, Lavras, MG, 2008.

\begin{tabular}{lcccc}
\hline Doses & Germinação & TF & IVE & Condutividade \\
\hline 0 & 71,12 & 40,62 & 4,76 & 152,78 \\
400 & 71,87 & 39,50 & 4,79 & 160,32 \\
600 & 74,75 & 41,62 & 4,70 & 154,18 \\
800 & 72,25 & 43,50 & 4,71 & 152,58 \\
1000 & 70,87 & 37,50 & 4,67 & 155,34 \\
\hline
\end{tabular}

Por meio desses resultados, verifica-se que o teor de Mo não interfere na qualidade das sementes. Entretanto, para este micronutriente, pouco se sabe sobre sua influência na qualidade fisiológica de sementes de soja. Contudo, sabese que, no caso específico de alguns nutrientes para certas espécies, é possível aumentar a qualidade fisiológica das sementes, a exemplo do teor de cálcio contido em sementes de amendoim, em que sua alta concentração deste favorece a germinação (Adams et al., 1993).

Observa-se que a qualidade das sementes da cultivar Conquista produzidas em Lavras (Tabela 1) foi superior à das sementes da cultivar CD-215, produzida em Ituiutaba (Tabela 2). Isto ocorreu, principalmente, em razão do excesso de chuvas que antecederam o período de colheita na região de Ituiutaba. Apenas o índice de velocidade de emergência foi semelhante em sementes produzidas nos dois ensaios.

\section{CONCLUSÕES}

O teor de Mo nas sementes de soja é crescente com a dosagem de Mo aplicada nas plantas independe da aplicação em dose única ou parcelada.

A adubação foliar com Mo durante o processo de maturação das sementes, com subsequente acúmulo desse nutriente na semente, não interfere na produtividade e na qualidade fisiológica das sementes de soja.

\section{REFERÊNCIAS BIBLIOGRÁFICAS}

ADAMS, F.M.; HARTOZOG, D.L.; NELSON, D.B. Supplemental calcium application on yield, grade, and seed quality of runner peanut. Agronomy Journal, Madison, v.85, p.86-93, 1993.

\section{ASSOCIAÇÃO BRASILEIRA DE SEMENTESE}

MUDAS. Disponível em: <http://Www.abrasem.com.br/>t. Acesso em: 10 maio 2008.
BRASIL. Ministério da Agricultura e Reforma Agrária. Regras para análise de sementes. Brasília, 1992. 365 p.

CÂMARA, G.M.S.; LUCHETI, M.P.; MARQUES, L.A.; PEDROSO, D.B.; NACAMURA, S.S.; BARROS, F.F. Desempenho vegetativo e produtivo da soja submetida à aplicação foliar de cobalto e molibdênio em diferentes estágios fenológicos no ano agrícola 2000/2001. In: CONGRESSO BRASILEIRO DE SOJA E MERCOSOJA, 2., 2002, Foz do Iguaçu. Resumos... Foz do Iguaçu: Embrapa, 2002. p. 222.

CAMPO, R.J.; HUNGRIA, M. Enriquecimento de sementes de soja com molibdênio como fator de aumento da eficiência da fixação biológica do nitrogênio e do rendimento da soja In: REUNIÃO DE PESQUISA DE SOJA DA REGIÃO CENTRAL DO BRASIL, 25., 2003, Uberaba. Resumos... Londrina: Embrapa, 2003. p. 156157.

CAMPO, R.J.; HUNGRIA, M. Utilização de sementes de soja enriquecidas com Mo: como e porque enriquecer. In: LATIN-AMERICAN CONFERENCE ON RHIZOBIOLOGY, 22., 2004, Miguel Pereira. Anais... Miguel Pereira, 2004. p. 13.

\section{COMPANHIA NACIONAL DE ABASTECIMENTO.} Disponível em: <http://www.conab.gov.br/y. Acesso em: 17 out. 2008.

FERREIRA, A.C.B.; ARAÚJO, G.A.A.; CARDOSO, A.A.; FONTES, P.C.R.; VIEIRA, C. Características agronômicas do feijoeiro em função do molibdênio contido na semente e da sua aplicação via foliar. Acta Scientiarum: Agronomy, Maringá, v.25, n.1, p.65-72, 2003.

FERREIRA, D.F. Análises estatísticas por meio do SISVAR para Windows ${ }^{\circledR}$ versão 4.0. In: REUNIÃO ANUAL DA REGIÃO BRASILEIRA DA SOCIEDADE INTERNACIONAL DE BIOMETRIA, 45., 2000, São Carlos. Resumos... São Carlos: UFSCar, 2000. p. 235.

FUNDAÇÃO DE APOIO À PESQUISA AGROPECUÁRIA DE MATO GROSSO. Boletim técnico de soja 2004. Rondonópolis, 2004. 231 p.

GUIMARÃES, R. M. Fisiologia de sementes. Lavras: UFLA/FAEPE, 1999. 129 p. 
HARRIS, H.B.; PARKER, M.B.; JOHNSON, B.J. Influence of molybdenum contento of soybean seed and other factors associated with seed source on progeny response to aplplied molybdenum. Agronomy Journal, Madison, v.57, p.397-399, 1965.

HUNGRIA, M.; CAMPO, R.J.; MENDES, I.C. Fixação biológica do nitrogênio na cultura da soja. Londrina: Embrapa Soja, 2001. 48p. (Embrapa Soja. Circular técnica, 35. Embrapa Cerrados. Circular técnica, 13).

JACOB-NETO, J.; ROSSETTO, C.A.V. Concentração de nutrientes nas sementes: o papel do molibdênio. Floresta e Ambiente, v.5, n.1, p.171-183, 1998.

LEITE, U.T.; PIRES, A.A.; ARAÚJO, G.A.A.; VIEIRA, R.F. Absorção de Mo e de $\mathrm{N}$ em diferentes variedades de feijão em função de doses de Mo. In: CONGRESSO NACIONAL DE PESQUISA DE FEIJÃO, 7., 2002, Viçosa, MG. Resumos... Viçosa, MG: UFV, 2002. p.814-817.
MAGUIRE, J.D. Speed of germination and relation evaluationfor seedling emergence vigor. Crop Science, Madison, v.2, p.176-177, 1962.

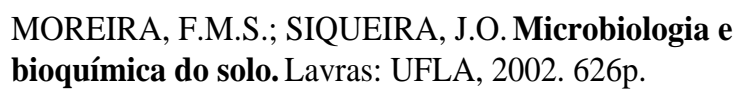

REUNIÃO DE PESQUISA DE SOJA DA REGIÃO SUL, 29., 2001, Porto Alegre. Indicações técnicas para a cultura de soja no Rio Grande do Sul e em Santa Catarina 2001/ 2002. Porto Alegre: FEPAGRO, 2001. 138p.

TAIZ, L.; ZEIGER, E. Plant phisilogy. 3.ed. Sunderland: Sinauer Associates, 2004. 792p.

VARGAS, M.A.T.; HUNGRIA, M. Biologia dos solos dos cerrados. Planaltina: Embrapa, 1997. 524p.

VIEIRA, F.V.; SALGADO, L.T.; RIGUEIRA, C.M.S. Produção de sementes de feijão com alto teor de molibdênio. In: CONGRESSO NACIONAL DE PESQUISA DE FEIJÃO, 7., 2002, Viçosa, MG. Resumos... Viçosa, MG: UFV, 2002. p.530-533. 